\title{
The Relationship of Help-Seeking Inclinations to Traditional Predictors of Academic Success and First-Semester College GPA
}

\author{
Michael J. Roszkowski
}

Inclination to seek help was measured among a cohort of first-time, full-time freshman at a private university prior to the start of their first semester. The item involved a 10-point scale defined with contrasting terms at each end (i.e., verbal anchors at the extremes). Approximately 78\% of the respondents rated themselves 5 and below, indicating a general reluctance to seek help. Males were less likely to seek help than females. Help-seeking inclinations were positively correlated with academic performance in high school, as reflected in class rank, but negatively related to SAT scores. An interaction was observed, indicating that students with high SAT and low high school rank were especially reluctant to look for help. The relationship of help-seeking predisposition to first semester college GPA was curvilinear, with the GPA rising with increasing proclivity to seek help until the highest level of help seeking, at which point it dropped.

Personnel involved in student orientation and transition try to provide new students with information on policies, procedures, programs, and support services. Frequently, however, the student will need to ask for additional assistance in order to take advantage of the available resources (Collins \& Sims, 2006). Help seeking has been implicated in how well students perform in college; however, further research is needed on how help seeking in college relates to ability factors and how well it predicts college outcomes in the first year of college. The first year is extremely critical because it constitutes the period during which the student is most at risk for attrition, with approximately half of all students who drop out from college doing so in their first year (Hermanowicz, 2003). Frequently, a low GPA is either the primary cause or at least a contributing factor (Kern, Fagely, \& Miller, 1998). The present study first examines the relationship between help seeking and SAT and high school rank. Next, it reports the extent to which self-reported proclivity to seek help, assessed prior to the start of classes, predicts freshman first semester college GPA.

Michael J. Roszkowski (roszkows@lasalle.edu) is the Assistant Provost for Evaluation Services at La Salle University. 


\section{Review of the Literature}

\section{Traditional Predictors of College Outcomes}

Traditionally, college admissions personnel have relied primarily on high school records, such as the GPA or class rank, and standardized aptitude test scores, such as the SAT, to determine an applicant's potential to succeed in college (Harackiewicz, Barron, Tauer, \& Elliot, 2002). In this process, the high school record is generally regarded as an indicator of prior achievement; whereas, the SAT is usually viewed as a measure of the potential to achieve. The relative weight assigned to each of these attributes in the decision to accept or reject an applicant varies by college, but Basten, Cole, Maestas, and Mason (1997) have demonstrated that SAT scores are the stronger predictor of most institutions' selection decisions.

\section{SAT vs. High School Record}

The value of these two indicators of the potential to achieve in college continues to be debated. Advocates of the SAT contend that the test is necessary because of large variations in the quality of the nation's high schools, grading standards, and rigor of the student's curriculum. Opponents of the SAT argue that past behavior, which is reflected in the high school record, is the best predictor of future behavior (Aleamoni, 1977; Beecher \& Fischer, 1999; Crouse \& Trusheim, 1991; Sacks, 1997). With some exceptions (e.g., Weitzman, 1982), the research confirms that the SAT adds only a little to the prediction of college success beyond the information already available in the high school record (Baron \& Norman, 1992; Crouse \& Trusheim, 1988; Dalton, 1976; Slack \& Porter, 1980).

\section{Low Degree of Predictability with Traditional Measures}

Even when taken together, however, the level of predictability afforded by the high school record and the SAT leaves much to be desired. At best, the validity coefficients are in the .5 range (Morgan, 1990; Mouw \& Khanna, 1993), meaning that only $25 \%$ of the variance in college grades can be explained by these measures. Part of the problem is measurement error (unreliability) in both the predictors and the criterion, but another reason is that a host of variables are responsible for success in college. Some researchers contend that these unmeasured attributes are noncognitive in nature, such as motivation (Pantages \& Creedon, 1978; Sedlacek, 2004; Tracey \& Sedlacek, 1987).

\section{Noncognitive Predictors}

In a meta-analysis, Robbins et al. (2004) studied the relationship of both college performance (usually the first year of college GPA) and persistence (retention/attrition) to noncognitive variables classified into nine broad types: achievement motivation, academic goals, institutional commitment, perceived 
social support, social involvement, academic self-efficacy, general self-concept, academic-related skills, and contextual influences. Their analysis indicated that academic self-efficacy $(r=.50)$ and achievement motivation $(r=.30)$ were the noncognitive variables most highly correlated with performance. In fact, academic self-efficacy was almost as strong a predictor as the best cognitive measure, namely high school grades. Moreover, it was a better predictor than entrance exam scores such as the SAT. With persistence as the criterion, the three best predictors were academic-related skills, academic self-efficacy, and academic goals $(r=.37, .36$, and .34 , respectively). Other variables, such as self-esteem, played no role.

One might expect that assessment of such additional variables would have become a standard part of an enhanced admissions process at most institutions; however, the value of noncognitive variables remains a matter of debate (see Bridges, 2001; Cubeta, Travers, \& Sheckley, 2001; Thomas, Kuncel, \& Credé, 2007; Sedlacek, 2004; Ting \& Sedlacek, 2000). The contribution of any single noncognitive characteristic to the improvement of the prediction of college success has been limited by the fact that, in most instances, such characteristics are correlated to high school record or SAT (Astin, 1971), so they add little incrementally to the prediction equation because they are redundant with the standard cognitive measures. However, considered together, they may allow for greater predictability of college outcomes. Recently, a renewed focus on the noncognitive variables has emerged and the search for supplemental measures continues (Burton \& Ramist, 2001; Oswald, Schmitt, Kim, Ramsay, \& Gillespie, 2004; Cirillo \& Smith, 2008; Shivpuri, Schmitt, Oswald, \& Kim, 2006).

\section{Help Seeking}

Help seeking is a noncognitive variable that has not received adequate attention in the literature on the noncognitive correlates of college outcomes (Lee, 2007; Mäkitalo-Siegl \& Fischer, 2011). Much of the research on academic help seeking is based on elementary and high school students, although it probably generalizes to college students (Karabenck \& Newman, 2006).

Desirability of help seeking. At one time, help seeking in academic tasks was viewed in quite a negative light by many educational psychologists, primarily being seen as a sign of dependency (Nolen, 1988). Today, however, it is recognized that help seeking can be productive and that it is part of the process of self-regulated learning (Newman, 1991, 1998a) and a characteristic of active learners (Karabenick \& Knapp, 1991). Moreover, students with a mastery orientation to learning are more likely to seek help than students with a task orientation (Ames \& Archer, 1988; Butler, 1993; Butler \& Neuman, 1995; Karabenick, 2003, 2004; Newman \& Schwager, 1995). In fact, help seeking is often used by even experts in their fields (Zimmerman, 1998, 2001).

Some determinants of decisions to seek help. Student grades and retention rates can improve when academic support is offered in the form of programs such as tutoring, academic advising or counseling, study skills instruction, supplemental instruction, and developmental courses (Hodges \& White, 2001; McKeachie, Pintrich, \& Lin, 1985). However, in most instances, the student must 
initiate the contact (Alexitch, 2002). In part, willingness to seek help is a function of classroom factors and teacher characteristics (Karabenick, 2004; Newman, 1998a; Ryan, Gheen, \& Midgley, 1998; Turner, et al. 2002; Urdan \& Schoenfelder, 2006). Butler (2008), for instance, found that ability tracking in elementary school discourages help seeking. Kitsantas and Chow (2007) report that, at the college level, there is less reluctance to seek help from instructors in online courses. However, personal beliefs and demographic characteristics appear to play a large role as well (Calarco, 2011; Gloria, Hird, \& Navarro, 2001; Nadler, 1998; Newman, 1990). It is well established that, relative to women, men are considerably more reluctant to seek help of all sorts, including academic problems (Addis \& Mahalik, 2003; Benenson, \& Koulnazarian, 2008; Roszkowski \& Ceraso, 2008). Culture also imposes beliefs about the appropriateness of help seeking (Nadler, 1998; Shwalb \& Sukemune, 1998; Volet \& Karabenick, 2006).

A disturbing finding is that students who are at risk are less likely than average students to ask for help (Arendale, 1994; Friedlander, 1980; Hodges \& White, 2001; Nelson-Le Gall, \& Glor-Scheib, 1985; Newman, 1990; Newman, \& Schwager, 1993; Stansbury, 2001; Taplin, et al., 2001; Wood \& Wood, 1999). According to Hodges and White (2001), one reason may be that high-risk students are not able to accurately assess their need for assistance. Task abandonment (giving up) may be another reason (Newman, 1998a). A third possible cause is that requesting help may constitute a reaffirmation of feelings of inadequacy for struggling students (Middleton \& Midgley, 1997; Newman, 1990; Ryan \& Pintrich, 1997).

Karabenick and Knapp (1988) propose that there is an inverted U-shaped relationship between the need for academic assistance and actual help seeking, such that students at either extreme of need are the least likely to seek help. In other words, both outstanding and failing students do not seek out help. It is obvious why this reluctance can hurt the student with low ability, but the highability student is also at risk under some circumstances. According to Newman (1998b), "adaptive" help seeking requires the recognition of some impediment in the learning process, but the college student with high ability may be overconfident and thereby underestimate the difficulty of some academic tasks. There is extensive literature regarding the student with high intelligence who nonetheless fails (Mandel \& Marcus, 1988). The reasons are varied, but failure to recognize the need for help is one possibility. Help seeking may also be low among high-ability students because they desire to maintain a favorable image of their intellectual prowess, which could suffer by requesting help (Butler, 2008; Nadler, 1998; Newman \& Schwager, 1995; Tessler \& Schwartz, 1972).

Taxonomies of help seeking. Perceptions of benefits and costs (threats) govern whether help is sought (Ryan \& Pintrich, 1997). Factor analytic research by Butler (1998) suggests that reluctance to seek help stems from either of two orientations to learning, which she calls (a) autonomous and (b) ability focused. Students with an autonomous orientation have a need for independence and prefer to learn on their own. Such students dislike becoming indebted to someone for the aid received. When they do ask for help, it is for "hints" or clarifications rather than complete answers. 
To students with an ability-focused orientation, on the other hand, asking for help means acknowledging a deficit or weakness. Because of a fear of being judged as inadequate or incompetent, they would rather cheat than get direct, overt help. Students with an ability-focused orientation, particularly the males, request help less often than students with an autonomous orientation. Another line of research shows that individuals who consider intelligence to be fixed rather than malleable are less likely to seek help when faced with a difficult learning task (Dweck, 1999).

Butler also identified what she called an "expedient" orientation. A student with the expedient orientation has little reluctance to seek aid, and may ask for help even when unnecessary. Even though such a person may be able to master the material independently, he or she asks for help excessively because learning on one's own requires too much time or effort. Students with the expedient orientation want complete answers, not just hints.

A related distinction that has been made in the literature is between "executive" versus "instrumental" help seeking (Nelson-Le Gall, 1981). Other terms researchers have used for the instrumental form of help seeking are adaptive, autonomous, and appropriate (e.g., Newman, 2006). In some studies, the executive form of help seeking has been called excessive, unnecessary, effort avoidant, and expedient (Karabenick, 2006). The primary distinctive feature of these two forms of help seeking lies in the underlying motivation. The instrumental help seeker wants only a limited amount of help, enough to allow him or her to learn the task. In contrast, the executive help seeker is similar to the student with the expedient orientation, identified by Butler (1998), who engages in excessive help seeking and wants someone else to provide the solutions to an academic task. Executive help seekers often become overly dependent on their teachers. Karabenick (2003) reports that students who equate seeking help with an admission of failure are more likely to use executive help seeking. Moreover, they are apt to rely on informal sources of help, such as a classmate or roommate, rather than more formal sources such as faculty or teaching assistants. Likewise, students who attribute failure to low ability rather than to inadequate effort are more likely to engage in executive help seeking (Magnusson \& Perry, 1992).

Another taxonomy differentiates between help seekers on the basis of how much help is sought, namely appropriate, avoidant, and dependent. In this nomenclature, avoidant help seeking appears to subsume Butler's (1998) abilityfocused and autonomous orientations, while the dependent help seeking category reflects her excessive orientation. Ryan, Patrick, and Shim (2005) examined the frequency of these three degrees of help seeking among sixth grade students. Teachers identified their prevalence as follows: $65 \%$ appropriate, $22 \%$ avoidant, and $13 \%$ dependent. Both the avoidant and dependent help-seekers had undesirable profiles on anxiety, academic efficacy, and achievement; however, the dependent help seekers exhibited good social relationships, like the appropriate help seekers; whereas, the avoidant help seekers did not. 
Much of the research documenting the positive relationship between help seeking and academic performance was conducted in the primary and secondary grades. At the college level, the research has mainly consisted of experiments conducted in specific classes. While, intuitively, one would think that the conclusions are generalizable to all grade levels, research at the college level on the relationship between help seeking and college GPA by McCarthy (2006) found a very low and statistically non-significant correlation of .047 between grades and the number of office visits students made to their professors for help. Both the GPA and number of visits were self-reports. The limitations in her study were that the sample size was small $(n=65)$, so there was low power to find significance for weak relationships, and also, there was no control for ability factors, such as SAT or high school achievement. Another limitation is that theoretically, the relationship between help seeking and GPA may not be linear, in which case, a Pearson correlation would underestimate the magnitude of the relationship.

\section{Assessing Help Seeking}

Although it is possible to get direct measures of help seeking, such as number of questions asked during class or office visits (or self reports of them), from a predictive standpoint, one needs an indicator that is available before the start of classes. As pointed out by Karabenick (2011), a question dealing with proclivities to seek help, therefore, has merit:

As in other psychological domains, conditional information-knowing what persons would do under a given set of circumstances-is often more important than observed or self-reported behavior. Accordingly, help seeking research has increasingly relied on students' responses to conditionally constrained statements that assess their intentions (e.g., "if I didn't understand a problem, I would ask my teacher for help"). This assessment strategy is consistent with evidence that properly formed intentions can predict subsequent behavior in a wide variety of domains (Fishbein \& Ajzen, 2010). (p. 269)

Single item measurement of help seeking. It is a well-established psychometric principle that reliability is a function of the number of items in a scale. Other things being equal, a larger number of items results in greater reliability. Consequently, multi-item scales are preferable to single item scales in measuring any given construct; however, sometimes it becomes necessary to measure an attribute with only a single item, such as when assessing a large number of constructs on a long questionnaire or if one wants to avoid fatigue or boredom (Denissen, Greenen, Selfhout, \& vanAken, 2008; Gosling, Rentfrow, \& Swann, 2003; Robins, et al., 2001).

The single-item approach sacrifices reliability for usability in situations that would place too high a demand on the participants if long scales of the various constructs were to be used. Despite their drawbacks, single item scales do allow for a simple and economical data collection mechanism, but this approach is probably more useful for screening and research purposes than for individual assessment. 
Taplin et al. (2001) successfully used a single item 5-point Likert scale to assess help seeking among distance education students ("I believe that help-seeking is a good way to learn and grow").

A 10-point scale to differentiate forms of help seeking. There is a rationale for using a 10 point scale. Too few options on an attitude question can result in low sensitivity and reliability, thereby not permitting for differentiating among people. Conversely, too many options can frustrate the respondent, which, in turn, can lead to measurement error and non-response. The literature on the optimal number of options in a survey was reviewed by Cox (1980), who concluded that there is no one format that is ideal under all circumstances, but that two and threepoint scales are generally inadequate, and any benefits resulting from more than nine response alternatives are marginal at best.

However, research by Alwin (1997) comparing a 7 to an 11-point scale format suggests that the 11-point scale does not necessarily lead to greater error. Likewise, Coelho and Esteves (2007) found that compared to a 5-point scale, the 10-point scale was superior on response rates and response distribution. In addition, it proved to be better in terms of convergent, discriminant and nomological validity. According to Knapp (1990), "10-point scales tend to 'continuize' things more than 5-point scales" (p. 123). Intuitively, a 10-point rating scale may allow one to differentiate between the appropriate, avoidant, and dependent forms of help seeking better than on the basis of a 5-point scale.

Moreover, 10-point scales seem to appeal to respondents. When Preston and Colman (2000) asked respondents to indicate which format they preferred when using rating scales ranging from 2 to 11 response categories, the most favored alternative was the 10-point scale. The popularity of the 10-point format appears to be growing, perhaps because, as Coelho and Esteves (2007) observed, the phrase "On a scale of 1 to 10 , how would you rate ...." is now part of the everyday lexicon.

\section{Issues Addressed in the Current Study}

Using a 10-point scale of help seeking predisposition, the current study sought answers to the following questions:

- How does help seeking relate to traditional predictors of academic success, namely SAT and high school class rank, singly and considered together?

- What is the relationship between degree of help-seeking inclination and first semester college GPA?

- Does the nature of the relationship between help seeking predispositions and first term GPA change once control is introduced for SAT, high school percentile rank, and gender?

\section{Method}

\section{Participants}

The sample consisted of first-time, full-time freshmen enrolling in the fall 
semester at a private regional university with the following Carnegie classifications: Undergraduate Instructional Program = Bal/SGC, Graduate Instructional Program= S-Doc/Other, Enrollment Profile: HU, Undergraduate Profile= FT4/S/HTI, Size and Setting: M4/HR, Basic: Master's L.

As part of the orientation day activities during the summer preceding their first semester at the university, the students completed a form that requested information meant to be useful in advising the student. For undetermined reasons, the survey was only completed by 691 of the 770 freshman, and four of them did not answer the question on help seeking. Moreover, either high school rank or SAT was unavailable for 340 of the students who did submit the form. Primarily, the rank was missing because the high school did not rank their students. This reduced the sample further to 347 for the analysis involving SAT and class rank. High school rank rather than high school GPA was used as a measure of high school performance primarily because grades based on different systems were recorded directly into the centralized file that served as the basis for the analysis (i.e., mix of letter, percentage, and numerical grades). Conversion to a common scale was not feasible because some of the numerical grades were not based on the traditional 4-point system, and it was not possible to tell if this was the case unless the grade was above a 4.0 .

\section{Help Seeking Question}

A single item was used to assess help seeking. It was part of a long survey intended to collect information that would be relevant in the advising process. The question was worded as follows in the survey: "When you experience problems, what are you most likely to do?" Below this sentence was a horizontal scale with equally spaced numbers from 1 to 10, arranged from left to right. The left side was labeled "work it out myself," and "seek counseling" appeared on the right side; thus, the higher the number, the greater the degree of help seeking.

\section{Results}

\section{Distribution of Help Seeking}

The overall distribution of help seeking predispositions, shown in the last column of Table 1, was skewed. A majority of respondents were on the half of the scale that reflected lower degrees of help seeking. Ratings of 1 through 5 represented close to $78 \%$ of the sample.

\section{Gender Differences in Help Seeking}

The self-ratings by women and men were compared (see Table 1 ) on the basis of a full crosstabulation $\left[\chi^{2}(9)=25.49, p=.002\right.$, Cramer's $\left.V=.19\right]$ as well as on mean scores $\left[F(1,682)=16.18, p=.000, \eta^{2}=.02\right]$. The percentage of men with ratings of 1 through 5 is higher relative to the women. For self-ratings of 6 
through 10 , the converse is true. The mean help seeking rating is $4.28(S D=2.32)$ for women and $3.59(S D=2.09)$ for men, indicative of men's lower level of help seeking.

\section{Relationship between Traditional Predictors of College GPA and Help Seeking}

Regression approach. The first question concerns the relationship of help seeking to SAT scores and high school percentile rank. To start the analysis, I conducted a multiple regression with the self-rated help-seeking predisposition score (1 through 10) as the criterion (dependent variable) and SAT and class rank as the predictors (independent variables). A number of models were considered. Since an examination of the raw data suggested that there may be an interaction between SAT and high school rank, I introduced an interaction term into the equation in the second model. In the first model, only SAT and rank served as the predictors, and with these two independent variables, the multiple correlation $(R)$ equaled .235 or .055 squared (.050 adjusted $R$ square). The model was statistically significant $[F(2,352)=10.31, p=.000]$, as were the Beta weights for SAT $(\beta=-.19$, $t=-3.39, p=.001)$ and $\operatorname{rank}(\beta=.23, t=4.06, p=.001)$.

The sign of the $\beta$ weight associated with an independent variable indicates whether it has a positive or negative relationship with the dependent variable, holding the other predictors constant. By comparing the $\beta$ weights, one can determine the relative predictive importance of the independent variables. The Beta weights for SAT and rank are about the same size (ratio of larger to smaller $=1.2$ ), but with opposite signs. The relationship between SAT and help seeking is negative; whereas, a positive relationship exists between rank and help seeking. The $\beta$ indicates the change in the dependent variable that occurs with each unit (SD) increase in the first predictor when the second predictor is held constant. Holding rank constant, an increase in the SAT score equal to one standard deviation drops the help seeking score by $19 \%$ of the value of its SD. Conversely, when SAT is controlled, each SD increase in class percentile rank raises the help seeking score by $23 \%$ of the help seeking SD.

The second model involved the predictors of SAT score and high school class rank, as was the case in Model 1, but an interaction term was added to the regression equation. The overall model was again statistically significant $[F(3,351)$ $=8.25, p=.000]$. The multiple correlation $(R)$ increased from .235 under model 1 to .257 under model 2 , a statistically significant change $[\Delta F(1,351)=3.97$, $p=.047$ ], which indicates that allowing for the interaction between SAT and rank improved the ability to predict help-seeking. In other words, the effects of SAT and rank on help seeking are not simply additive. That is, the interaction of SAT and rank indicates that the effect of SAT on help seeking is not the same at different values of the class rank. This situation can also be described as indicating that the slope of the regression lines between SAT and help seeking are different for different class ranks.

The resultant Betas were -.61 for SAT $(t=-2.80, p=.005),-.72$ for rank $(t=$ 
$-1.51, p=.133)$, and 1.17 for the interaction term $(t=1.99, p=.047)$. Interpreting the Beta coefficients of SAT and rank in the presence of interactions is not as straightforward as when there is no interaction term present (Model 1). The reported Beta for SAT $(\beta=-.61)$ only shows the effect of SAT on help seeking when the class rank equals zero. Likewise, the weight for $\operatorname{rank}(\beta=-.72)$ represents the effect of rank on help seeking when the SAT is zero. Since SAT can never equal zero, it is not possible to interpret the effect of rank under this condition. The size of the Beta weight for the interaction relative to the independent variables shows how different help seeking is under various combinations of SAT and rank.

This interaction was analyzed and graphed using the procedure recommended by Aiken and West (1991), employing a program available at http://www. jeremydawson.co.uk/. The unstandardized regression coefficients used for this purpose had the following values: $\mathrm{SAT}=-.01102$, rank $=-.08415$, interaction $=.00011$. The specific impact that SAT imparts on help seeking at different class rank values is given by following formula: SAT effect $=-.01102+\left(.00011{ }^{*}\right.$ rank $)$. Correspondingly, the impact of rank at various values of SAT is found with the following formula: rank effect $=-.08415+(.00011 *$ SAT $)$. This interaction is plotted in Figure 1. The help seeking values corresponding to the data points on the graph are High Rank-Low SAT= 4.78, High Rank- High SAT= 4.48, Low Rank- Low $\mathrm{SAT}=4.13$, Low Rank-High SAT=2.85. The interaction is ordinal, but the students with high SAT scores but low class ranks are by far the least likely to seek help.

ANOVA with median split. To get a more intuitively appealing perspective on this relationship, an ANOVA model was applied to the data in which both SAT and high school rank were divided into low and high scores on the basis of a median split. Help seeking was significantly different in terms of both independent variables as well as on their interaction: SAT $[F(1,351)=5.81, p=.016$, partial $\eta^{2}=.02$, observed power $\left.=.67\right], \operatorname{rank}\left[F(1,351)=9.42, p=.002\right.$, partial $\eta^{2}=.03$, observed power $=.87]$, interaction $\operatorname{rank}\left[F(1,351)=4.43, p=.036\right.$, partial $\eta^{2}=.01$, observed power $=.56]$.

Table 2 presents the mean help seeking scores in terms of these variables. The main effects suggest that as SAT increases, help seeking goes down. Conversely, as high school rank goes up, so does help seeking. The significant interaction, however, suggests that it is most informative to look at the combinations of these two variables. Inspection of Table 2 reveals that the Low Rank-High SAT group had the lowest level of help seeking $(M=2.80)$; whereas, the opposite configuration of High Rank -Low SAT has the highest level of help seeking $(M=4.13)$. Under three different post hoc tests (LSD, Bonferroni, Tamhane), the help seeking of the Low Rank-High SAT group is significantly lower than that of the remaining three groups. Having high SAT scores and low rank is associated with lower willingness to seek help than either variable alone would suggest.

It is relevant to note that this relationship is not due to the confounding effects of sex. I compared the prevalence of the four patterns among women and men, and they were, respectively, Low Rank-Low SAT=33\% vs. 35\%, Low Rank-High SAT= $12 \%$ vs. 19\%, High Rank-Low SAT=20\% vs. 17\%, High Rank-High SAT=35\% vs. $29 \%$. A chi-square test did not identify these differences as statistically significant $\left[\chi^{2}(3)=5.52, p=.137\right]$. Even more convincing is the finding that the Low Rank- 
High SAT students had the lowest mean help seeking scores within their own gender (Males $=2.65$, Females $=2.96$ ); whereas, the High Rank-Low SAT group had the highest average help seeking scores for their sex (Males $=3.78$, Females $=4.32$ ).

\section{Nature of the Relationship between GPA and Help Seeking}

GPA and help seeking in entire sample. First term GPA was determined to vary as a function of the 10-point help seeking inclination rating $[F(9,659)=2.47$, $p=.009$, partial $\eta^{2}=.03$, observed power $\left.=.93\right]$. LSD follow-up tests identified 10 statistically significant pairwise differences. This post hoc procedure showed that the mean GPA achieved by students assigning themselves the lowest help-seeking inclination rating of $1(\mathrm{GPA}=2.82)$ was significantly different from the average GPA of students with self ratings of $3(\mathrm{GPA}=3.04), 4(\mathrm{GPA}=3.15)$, and $7(\mathrm{GPA}=3.17)$. The GPA of students with self-ratings of 2 differed from that of students with self ratings of 4 and 7 . The students with a help seeking inclination rating of 10 $(\mathrm{GPA}=2.61)$ differed the most in terms of GPA from the others, with significant differences occurring between them and the groups with help seeking ratings of 3 , $4,6,7$, and 8 . Tamhane's T2, a more conservative pairwise comparisons test also based on the t test, shows only one pair to be significantly different, namely ratings of 1 versus 4 .

It must be recognized, however, that the low sample size in some cells does not allow enough power to pick up small differences. Generally, the pattern to the data suggests a trend with better first term GPAs with increasing help seeking up until a help seeking rating of 10 is reached, at which point the GPA drops to a level that is descriptively even lower than the one for the group with a help seeking rating of 1 . Descriptively, the lowest ratings occur at the extremes, at help seeking self-ratings of 10 and 1.

Predictors of GPA. The simple correlations between SAT, high school rank, and GPA were calculated for all available cases (pairwise deletions). On the basis of 605 cases, the Pearson correlation between first term GPA and SAT was .24 ( $p$ $=.000$ ). Based on the 389 cases that had high school rank percentiles available, the correlation between GPA and rank variable was a bit larger, $r=.40$. The correlation between SAT and high school rank was .37 $(p=.000)$, based on 357 cases.

The number of cases that had SAT and high school rank, along with self-rated help seeking was 347 . To determine if the subsample is atypical, a comparison was made between the distribution of help-seeking predispositions among the 347 cases without missing values and the 337 cases with missing values. The distributions were not significantly different $\left[\chi^{2}(9)=9.19, p=.420,2\right.$ cells $(10.0 \%)$ have expected count less than 5. The minimum expected count is 3.94]. Moreover, computed on this subsample, the correlation between GPA and SAT was similar $(r=.23)$ to the one in the full sample $(r=.24)$. Likewise, the correlation between GPA and high school rank was about the same $(r=.41)$. SAT and high school rank correlated at $r=.36$. In other words, despite the missing data, there was no evidence to suggest that the subsample is atypical. 
Several additional relationships can be reported for this subsample. Help seeking and rank correlated at .16 $(p=.003)$, while the correlation between help seeking and SAT was a negative $10(p=.063)$. The Pearson correlation between GPA and help seeking was .11 ( $p=.045)$; however, a Pearson correlation is not the appropriate statistic, given the non-linear nature of the relationship between first term GPA and help seeking. Examination of the data in Table 3 shows that help seeking ratings of 10 introduce a non-linear element to the relationship with GPA; therefore, the relationships between these variables were examined again in the 340 cases that excluded the seven cases with help seeking ratings of 10 . The new correlation between first term GPA and help seeking was higher, $r=.21(p=.000)$. The other correlations remained relatively unchanged: GPA-SAT $=.23$ $(p=.000)$, GPA-rank $=.43(p=.000)$, SAT-help seeking $=-.07(p=.214)$, rank-help seeking $=.16(\mathrm{p}=.003)$. In other words, the relationship between help seeking and GPA was stronger if the most extreme help-seeking group is excluded, but the other relationships stayed about the same.

It was also observed, in both the sample and the subsample, that gender and GPA are related, with women obtaining significantly higher GPAs. Using all 672 cases with a GPA, one finds that the average first term GPA for the female student is $3.16(S D=.62)$ compared to $2.73(S D=.81)$ for the male student $[F(1,670)=$ $\left.29.70, p=.000, \eta^{2}=.08\right]$. Similarly, in the subsample of 347 , women obtained an average GPA of $3.25(S D=.57)$; whereas, men averaged $2.81(S D=.79)$, a statistically significant difference $\left[F(1,345)=36.32, p=.000, \eta^{2}=.10\right)$. In terms of a point-biserial correlation between sex and first-term GPA, the magnitude of the relationship is .29 in the sample and .31 in the subsample.

Multiple regression predicting GPA. Table 4 presents the profile of each of the 10 help-seeking inclination groups in terms of the SAT, high school rank, first semester college GPA, and sex (percent female). These variables were the basis for a multiple regression in which SAT, rank, and gender served as the predictors of the first term GPA. A hierarchical approach was used, with four models. In the first model, the only predictors were SAT and high school percentile rank. The second model added sex to the predictors. In the third model, help seeking was also included, resulting in four predictors. The fourth model introduced the polynomial term for help seeking to account for the nonlinear relationship between help seeking and first term GPA.

The results of the four models are summarized in Table 5. Each model was statistically significant [ Model 1: $F(2,344)=35.90, \mathrm{p}=.000$; Model 2: $F(3,343)=36.71, \mathrm{p}=.000$; Model 3: $F(4,342)=27.49, \mathrm{p}=.000$; Model 4: $F(5,341)=24.68, \mathrm{p}=.000]$. Adding just help seeking did not lead to a change in $R$, with the multiple correlation in both Model 2 and Model 3 remaining at 493 . However, adding the curvilinear term for help seeking to the equation led to an increase in $R$ from .493 to .515 .

The standardized regression (Beta) weights and their statistical significance in each model are shown in Table 5. Beta weights change as new variables are introduced because they reflect the independent contribution of each variable to the prediction of the criterion, holding the other predictors constant. In Model 1, the Beta weight for high school percentile rank is almost four times as large as the 
one for the SAT, and the statistical significance of the weight for SAT is marginal. In other words, high school percentile rank is about four times better in its ability to predict first term college GPA than the SAT.

When sex is introduced into the picture (Model 2), the weight of high school rank is still the largest one, indicating that holding the other two variables constant, rank remains the most important predictor of first-term college GPA. Sex becomes the second best predictor, while SAT is third. The negative weight for sex occurs because females were coded as 0 and males as 1 , and lower GPAs are associated with males.

Adding help seeking to the set of predictors (Model 3) seems to do little. In Model 3, the help seeking Beta is very small and not statistically significant. In other words, it appears to be a useless predictor; however, this is due to the curvilinear relationship between GPA and help seeking that results at the rating of 10 on help-seeking inclination. Once the polynomial term for help seeking is introduced (Model 4), this variable becomes not only a significant predictor, but the one with the largest Beta. That is, help seeking becomes the strongest predictor of first term GPA when holding SAT, rank, and sex constant.

Residuals. Another perspective on the value of help seeking in the prediction of first semester GPA may be gained by using SAT, rank, and sex as the predictors (Model 2) and comparing the actual and predicted GPAs across the 10 help-seeking inclination ratings. This analysis is summarized in Table 6. The actual GPA of students with help seeking self-ratings of 1 and 2 are lower than expected on the basis of the three predictor variables (SAT, rank, sex). The actual GPA scores of students with help seeking ratings between 2 and 9 are higher than predicted, with a pattern of increasing residuals with higher help seeking scores, up until one reaches the rating of 10, at which point the actual score is lower than predicted. Again, this implicates help seeking in GPA, but in a curvilinear relationship.

An attempt was made to classify the sample into appropriate, avoidant, and dependent help seekers on the basis of the residual in Table 6 . If the residual is negative, that can be interpreted to mean that the help seeking level is inappropriate. In other words, the individual received first term college grades that are worse than would be expected on the basis of the person's sex, SAT, and high school record. As may be observed in Table 6, the negative residuals occurred at help seeking ratings of 1,2 , and 10 . Ratings at the lower end $(1,2)$ of the 10 point continuum probably signify the avoidant help seeker; whereas, a 10 appears to be indicative of the dependent help seeker. In the sample of 683, the distribution (see Table 1) of help seeking is thus $29 \%$ avoidant, $2 \%$ dependent, and $69 \%$ appropriate.

\section{Discussion}

The role of the orientation and transition professional is to facilitate the student's adjustment to a college environment. As noted by Collins and Simms (2006), guiding students on when and where they should seek help if experiencing a difficult situation is a critical function of that role, and having a good understanding of the dynamics of help-seeking behavior should enhance 
that process. Generally, for most people, help seeking causes discomfort (Bohns \& Flynn, 2010) because it requires admitting a weakness and poses a threat to selfesteem (Lin, 2002; Marchand \& Skinner, 2007). Consequently, it is not surprising that the majority of students prefer not to request help. In the present study, when asked to self-assess their level of help seeking on a 10-point scale, nearly $78 \%$ rated themselves using points on the lower half of the scale. Also consistent with a majority of previous studies, males in the present sample are inclined to seek help to a lesser extent than females.

An analysis was conducted to determine the relationship of help-seeking predispositions to SAT scores and to the student's high school performance. A positive relationship exists between help-seeking inclinations and high school class rank; whereas, there is a negative relationship between help seeking and SAT scores. That is, the better the class rank, the more likely a person is to seek help. Conversely, the higher the SAT score, the less inclined the individual is to seek help. However, the effect of high school rank and SAT was interactive such that the students least likely to seek help are ones with high SAT scores and low class ranks. Their reluctance to seek help is greater than would be predicted simply on the additive basis of their SAT scores and high school rank. Students with this sort of profile are unlikely to seek help on their own and, therefore, are ideal candidates for intrusive advising (Earl, 1988).

The traditional predictors of college GPA are high school record and SAT scores. On the basis of just a single predictor, the first semester GPA could be predicted much better on the basis of the high school rank than on the SAT scores. Together, however, SAT and high school record predict better than either variable alone, as one might expect. The relationship between first semester college GPA and help-seeking predisposition was non-linear. Adding help seeking inclinations to the model using a polynomial term improved the predictability of GPA beyond what is possible with just SAT scores and high school ranks, but the improvement was very minor because help seeking is related to these two other predictors. Once SAT, high school rank and sex are held constant, the independent contribution of help-seeking predisposition to explaining first-term college GPA is, in fact, very impressive. GPA increased with increasing degrees of willingness to seek help, but at the most extreme level of help seeking (10), the GPA dropped. Both very low and very high degrees of help seeking impair GPA. The results thus confirmed the curvilinear relationship between help seeking and grades identified by Karabenick and Knapp (1988) on a different basis.

It is noteworthy that the SAT scores of the group with help-seeking inclination ratings of 10 were considerably lower than average, but their high school class ranks were not. One has to wonder why they were more successful in high school than in college. Perhaps teachers were generous to them because these students established personal relationships with their instructors through a high level of interaction or perhaps because perceived effort was rewarded. The second question is why didn't that work in college?

According to Karabenick and Knapp (1991), the majority of help seeking in college is an appropriate rather than a dependent behavior. The distribution of avoidant, dependent, and appropriate help seekers, as determined on the 
basis of the residuals, in the present sample matches the distribution in sixth grade reported by Ryan, Patrick, and Shim (2005). They found 22\% avoidant, $65 \%$ appropriate, and $13 \%$ dependent. Our respective rates are $29 \%$, 69\%, and $2 \%$. The number of appropriate help seekers is remarkably close, but I found a greater proportion of avoidant and a lower proportion of dependent help seekers. However, in both studies, the avoidant type is more prevalent than the dependent type. Admittedly, one may question the use of residual scores to infer the levels of help seeking classifications made by Ryan, Patrick, and Shim (2005), but the similarity in the pattern is intriguing.

Although the individual differences in attitudes and preferences for seeking help exert a powerful influence on behavior, one needs to keep in mind that the classroom teacher can, in fact, also facilitate or hinder help seeking. Teachers can foster adaptive help seeking by creating a classroom climate that encourages questioning, not ridiculing students who experience academic difficulties, and demonstrating how collaboration is essential (Karabenick \& Sharma, 1994; Nelson-Le Gall \& Resnick, 1998; Newman \& Goldin, 1990). Emphasizing the intrinsic value of learning (competence) instead of learning for the sake of getting good grades (performance) also encourages adaptive help seeking (Karabenick, 2004).

\section{Limitations}

Theoretically, the exclusion of students without a high school rank may limit the generalizability of the results; it would be fruitful to explore the questions addressed here using high school GPA instead of class rank, particularly in view of the fact that the trend is for high schools not to rank their graduates (Finder, 2006). Moreover, high school percentile rank and perhaps the 10-point scale soliciting a self-assessment of inclination to seek help are at the ordinal level of measurement. Concerns have been raised in the literature about subjecting ordinal variables to parametric statistical procedures; however, there is sufficient evidence to show that use of parametric statistical procedures with ordinal data is typically not a problem (see Carifio \& Perla, 2008; Gaito, 1980; Norman, 2010). The reliability of the single item measure of help seeking is unknown, and the observed relationships may be attenuated by measurement error given the typical unreliability of single item measures of any construct.

\section{References}

Addis, M.E., \& Mahalik, J.R (2003). Men, masculinity, and the contexts of help seeking. American Psychologist, 58, 5-14.

Aiken, L. S., \& West, S. G. (1991). Multiple regression: Testing and interpreting interactions. Newbury Park, London: Sage.

Alexitch, L.R. (2002). The role of help-seeking attitudes and tendencies in students' preferences for academic advising. Journal of College Student Development, 43, 5-19. 
Aleamoni, L. M. (1977). Can grade point average be more accurately predicted? Journal of Psychology, 69, 225-227.

Alwin, D. F. (1997). Feeling thermometers versus 7-point scales - which are better. Sociological Methods \& Research, 25, 318-340.

Ames, C., \& Archer, J. (1988). Achievement goals in the classroom: Students' learning strategies and motivational processes. Journal of Educational Psychology, 80, 260-267.

Arendale, D. R. (1994). Understanding the supplemental instruction model. In D.C. Martin \& D. R. Arendale (Eds.), Supplemental Instruction: Increasing achievement and retention (pp. 11-22). San Francisco, CA: Jossey-Bass.

Astin, A. W. (1971). Predicting academic performance in college. Washington, DC: American Council on Education.

Baron, J. \& Norman, F. (1992). SATs, achievement tests, and high school class rank as predictors of college performance. Educational and Psychological Measurement, 52, 1047-1055.

Basten, J., Cole, H., Maestas, R., \& Mason, K. (1997, November). Redefining the virtuous cycle: Replacing the criterion of race with socioeconomic status in the admissions process in highly selective institutions. Paper presented at the 22nd Annual Conference of the Association for the Study of Higher Education, Albuquerque, NM.

Beecher, M. \& Fischer, L. (1999). High school courses and scores as predictors of college success. The Journal of College Admissions, Spring/Summer, 4-9.

Benenson, J. F., \& Koulnazarian, M. (2008). Sex differences in help-seeking appear in early childhood. British Journal of Developmental Psychology, 26, 163-169.

Bohns, V. K., \& Flynn, F. J. (2010). "Why didn't you just ask?" Underestimating the discomfort of help-seeking. Journal of Experimental Social Psychology, 46, 402-409.

Bridges, K. R. (2001). Using attributional style to predict academic performance: how does it compare to traditional methods? Personality and Individual Differences, 31, 723-730.

Burton, N. W., \& Ramist, L. (2001). Predicting success in college: SAT ${ }^{\circledR}$ studies of classes graduating since 1980. College Board Report 2001-2002. New York, NY: College Board.

Butler, R. (1993). Effects of task and ego achievement goals on information seeking during task engagement. Journal of Personality and Social Psychology, 65, 18-31.

Butler, R. (1998). Determinants of help seeking: Relations between perceived reasons for classroom help-avoidance and help-seeking behaviors in an experimental context. Journal of Educational Psychology, 90, 630-643.

Butler, R. (2008). Ego-involving and frame of reference effects of tracking on elementary school students' motivational orientations and help seeking in math class. Social Psychology of Education, 11, 5-23.

Butler, R. \& Neuman, 0. (1995). Effects of task and ego achievement goals on help seeking behaviors and attitudes. Journal of Educational Psychology, 87, 261-271.

Calarco, J. M. (2011). "I need help!" Social class and children's help-seeking in elementary school. American Sociological Review, 76, 862-882. 
Carifio, J. \& Perla, R. (2008). Resolving the 50-year debate around using and misusing Likert scales. Medical Education, 42, 1150-1152.

Cirillo, M. \& Smith, T. (2008). The development of a biographical inventory for use in the prediction of first-year college success. TCNJ Journal of Student Scholarship, 10, 1-11. Retrieved from http://www.tcnj.edu/ joss/2008/2008\%20Cirillo\%20and\%20Smith.pdf

Coelho, P.S., \& Esteves, S.P. (2007). The choice between a five-point and a ten-point scale in the framework of customer satisfaction measurement. International Journal of Market Research, 49, 313-339.

Collins, W., \& Sims, B.C. (2006). Help seeking in higher education support services. In S.A. Karabenick, \& R.S. Newman, (Eds.), Help seeking in academic settings: Goals, groups, and contexts (pp. 203-224). Mahwah, NJ: Laurence Erlbaum Associates.

Cox, E. P. (1980). The optimal number of response alternatives for a scale: A review. Journal of Marketing Research, 17, 407-422.

Crouse, J., \& Trusheim, D. (1988). The case against the SAT. Chicago, IL: University of Chicago Press.

Crouse, J. \& Trusheim, D. (1991). How colleges can correctly determine selection benefits from the SAT. Harvard Educational Review, 61(2), 125-147.

Cubeta , J. F., Travers, N. L., \& Sheckley, B.G. (2001). Predicting the academic success of adults from diverse populations. Journal of College Student Retention: Research, Theory and Practice, 2 (4), 295-311.

Dalton, S. (1976). A decline in the predictive validity of the SAT and high school achievement. Educational and Psychological Measurement, 36, 445-448. Denissen, J. J. A., Geenen, R., Selfhout, M., \& van Aken, M. A. G. (2008). Single-item big five ratings in a social network design. European Journal of Personality, 22, 37-54.

Dweck, C. S. (1999). Self-theories: Their role in motivation, personality, and development. Philadelphia, PA: Psychology Press.

Earl, W. R. (1988). Intrusive advising of freshmen in academic difficulty. NACADA Journal, 8 (2), 27-33.

Finder, A. (2006, March 5). Schools avoid class ranking, vexing colleges. New York Times. Retrieved from http://www.nytimes.com

Fishbein, M., \& Ajzen, I. (2010). Predicting and changing behavior: The reasoned action approach. New York, NY: Psychology Press.

Friedlander, J. (1980). Are college support programs and services reaching high-risk students? Journal of College Student Personnel, 21, 23-28.

Gaito J. (1980). Measurement scales and statistics: Resurgence of an old misconception. Psychological Bulletin, 87, 564-567.

Gloria, A. M., Hird, J. S., \& Navarro, R. L. (2001). Relationships of cultural congruity and perceptions of the university environment to help-seeking attitudes by sociorace and gender. Journal of College Student Development, 42, 545-562.

Gosling, S. D., Rentfrow, P. J., \& Swann, W. B. Jr. (2003). A very brief measure of the Big-Five personality domains. Journal of Research in Personality, 37, 504-528. 
Harackiewicz, J. M., Barron, K. E., Tauer, J. M., \& Elliot, A. J. (2002). Predicting success in college: A longitudinal study of achievement goals and ability measures as predictors of interest and performance from freshman year through graduation. Journal of Educational Psychology, 94, 562-575.

Hermanowicz, J. C. (2003). College attrition at American research universities: Comparative case studies. Flemington, NJ: Agathon Press.

Hodges, R., \& White, W. G. (2001). Encouraging high-risk student participation in tutoring and Supplemental Instruction. Journal of Developmental Education, 24 (3), 2-10.

Karabenick, S. A. (2003). Seeking help in large college classes: A person-centered approach. Contemporary Educational Psychology, 28, 37-58.

Karabenick, S. A. (2004). Perceived achievement goal structure and college student help seeking. Journal of Educational Psychology, 96, 569-581.

Karabenick, S. A. (2006). Introduction. In S.A. Karabenick, \& R.S. Newman, (Eds.), Help seeking in academic settings: Goals, groups, and contexts (pp. 1-14). Mahwah, NJ: Laurence Erlbaum Associates.

Karabenick, S. A. (2011). Methodological and assessment issues in research on help seeking. In B. J. Zimmerman \& D. H. Schunk (Eds.), Handbook of self-regulation of learning and performance. (pp. 267-281). New York, NY: Taylor \& Francis.

Karabenick, S. A., \& Knapp, J. R. (1988). Help seeking and the need for academic assistance. Journal of Educational Psychology, 80, 406-408.

Karabenick, S. A., \& Knapp, J.R. (1991). Relationship of academic help seeking to the use of learning strategies and other instrumental achievement behavior in college students. Journal of Educational Psychology, 83, 221- 230.

Karabenick, S. A. \& Newman, R. S. (2006) (Eds.) Help seeking in academic settings: Goals, groups, and contexts. Mahwah, NJ: Laurence Erlbaum Associates.

Karabenick, S. A., \& Sharma, R. (1994). Perceived teacher support of student questioning in the college classroom: Its relation to student characteristics and role in the classroom questioning process. Journal of Educational Psychology, 86, 90-103.

Kern, C. W., Fagely, N. S., \& Miller, P. M. (1998). Correlates of college retention and GPA: Learning and study strategies, testwiseness, attitudes, and ACT. Journal of College Counseling, 1, 26-34.

Kitsantas, A., \& Chow, A. (2007). College students' perceived threat and preference for seeking help in traditional, distributed, and distance learning environments. Computers \& Education, 48, 383-395.

Knapp, T. R. (1990). Treating ordinal scales as interval scales: An attempt to resolve the controversy. Nursing Research, 39, 121-123.

Lee, C. J. (2007). Academic help seeking: Theory and strategies for nursing faculty. Journal of Nursing Education, 46, 468-475.

Lin, Y. N. (2002). Taiwanese university students' perspectives on helping. Counseling Psychology Quarterly, 15, 47-58.

Magnusson, J. L. \& Perry, R. P. (1992). Academic help-seeking in the university setting: The effects of motivational set, attributional style, and help source characteristics. Research in Higher Education, 33, 227-245. 
Mäkitalo-Siegl, K., \& Fischer, F. (2011). Stretching the limits in help-seeking research: Theoretical, methodological, and technological advances. Learning and Instruction, 21, 243-246.

Mandel, H. P., \& Marcus, S.I. (1988). The psychology of underachievement: Differential diagnosis and treatment. New York, NY: John Wiley \& Sons.

Marchand, G., \& Skinner, E. (2007). Motivational dynamics of children's academic help-seeking and concealment. Journal of Educational Psychology, 99, 65-82.

McCarthy, M. (2006). Achievement goals effect academic success and help seeking behavior of undergraduates (Unpublished master's thesis). Rowan University, Glassboro, NJ. Retrieved from http://www.rowan.edu/library/rowan_theses/RU2006/0055ACHI.pdf

McKeachie, W. J., Pintrich, P. R., \& Lin, Y. (1985). Teaching learning strategies. Educational Psychologist, 20, 153-160.

Middleton, M. J., \& Midgley, C. (1997). Avoiding the demonstration of the lack of ability: An under-explored aspect of goal theory. Journal of Educational Psychology, 89, 710-718.

Morgan, R. (1990). Analyses of predictive validity within student categorizations. In W. W. Willingham, C. Lewis, R. Morgan \& L. Ramist (Eds.), Predicting college grades: An analysis of institutional trends over two decades (pp. 225-238).

Princeton, NJ: Educational Testing Service.

Mouw, J. T., \& Khanna, R. K. (1993). Prediction of academic success: A review of the literature and some recommendations. College Student Journal, 27, 328-336.

Nadler, A. (1998). Relationship, esteem, and achievement perspectives on autonomous and dependent help-seeking. In S. A. Karabenick (Ed.), Strategic help-seeking: Implications for learning and teaching (pp. 61-93). Mahwah, NJ: Lawrence Erlbaum Associates.

Nelson-Le Gall, S. (1981). Help-seeking: An understudied problem-solving skill in children. Developmental Review, 1, 224-246.

Nelson-Le Gall, S., \& Glor-Scheib, S. (1985). Help seeking in elementary classrooms: An observational study. Contemporary Educational Psychology, 10, 58-71.

Nelson-Le Gall, S., \& Resnick, L. (1998). Help-seeking, achievement motivation, and the social practice of intelligence in school. In S. A. Karabenick (Ed.), Strategic help-seeking: Implications for learning and teaching (pp. 39-60). Hillsdale, NJ: Lawrence Erlbaum Associates.

Newman, R. S. (1990). Children's help seeking in the classroom: The role of motivational factors and attitudes. Journal of Educational Psychology, 82, 71-80.

Newman, R. S. (1991). Goals and self-regulated learning: What motivates children to seek academic help? In M. L. Maehr \& P. R. Pintrich, (Eds.), Advances in motivation and achievement: A research annual (Vol. 7, pp. 151-183). Greenwich, CT: JAI Press.

Newman, R. S. (1998a). Students' help seeking during problem solving: Influences of personal and contextual achievement goals. Journal of Educational Psychology, 90, 644- 658. 
Newman, R. S. (1998b). Adaptive help seeking: A role of social interaction in selfregulated learning. In S.A. Karabenick, (Ed.), Strategic help seeking: Implications for learning and teaching (pp. 13-37). Mahway, NJ: Lawrence Erlbaum Associates.

Newman, R. S. (2006). Students' adaptive and nonadaptive help seeking in the classroom: Implications for the context of peer harassment. In S.A. Karabenick, \& R.S. Newman, (Eds.), Help seeking in academic settings: Goals, groups, and contexts (pp. 225-258). Mahwah, N.J.: Laurence Erlbaum Associates.

Newman, R. S., \& Goldin, L. (1990). Children's reluctance to seek help with schoolwork. Journal of Educational Psychology, 82, 92-100.

Newman, R. S., \& Schwager, M. T. (1993). Students' perceptions of the teacher and classmates in relation to reported help seeking in math class. The Elementary School Journal, 94, 3-17.

Newman, R. S., \& Schwager, M. T. (1995). Students' help seeking during problem solving: Effects of grade, goal, and prior achievement. American Educational Research Journal, 32, 352-376.

Nolen, S.B. (1988). Reasons for studying: Motivational orientations and study strategies. Cognition and Instruction, 5, 269-287.

Norman , G. (2010). Likert scales, levels of measurement and the "laws" of statistics. Advances in Health Sciences Education, 15, 625-632.

Oswald, F. L., Schmitt, N., Kim, B. H., Ramsay, L. J., \& Gillespie, M. A. (2004). Developing a biodata measure and situational judgment inventory as predictors of college student performance. Journal of Applied Psychology, 89, 187-207.

Pantages, T. J., \& Creedon, C. F. (1978). Studies of college attrition: 1950-1975. Review of Educational Research, 48, 49-101.

Preston, C. C., \& Colman, A. M., 2000. Optimal number of response categories in rating scales: reliability, validity, discriminating power, and respondent preferences. Acta Psychologica 104, 1-15.

Robbins, S. B, Lauver, K., Le, H., Davis, D., Langley, R., \& Carlstrom, A. (2004). Do psychological and study skill factors predict college outcomes? A metaanalysis. Psychological Bulletin, 130, 261-288.

Robins, R. W., Hendin H. M., \& Trzesniewski, K. H. (2001). Measuring global selfesteem: Construct validation of a single-item measure and the Rosenberg SelfEsteem scale. Personality and Social Psychology Bulletin, 27, 151-161.

Roszkowski, M. J., \& Ceraso, T. (2008, April 30). Leading horses to water: Male reluctance to participate in a peer mentorship program. Mentor. Retrieved from http://dus.psu.edu/mentor/

Ryan, A. M., Gheen, M. H., \& Midgley, C. (1998). Why do some students avoid asking for help? An examination of the interplay among students' academic efficacy, teachers' social-emotional role, and the classroom goal structure. Journal of Educational Psychology, 90, 528-535.

Ryan, A. M., \& Pintrich, P. R. (1997). "Should I ask for help?": The role of motivation and attitudes in adolescents' help seeking in math class. Journal of Educational Psychology, 89, 329-341. 
Ryan, A. M., Patrick, H., \& Shim, S. O. (2005). Differential profiles of students identified by their teacher as having avoidant, appropriate, or dependent helpseeking tendencies in the classroom. Journal of Educational Psychology, 97, 275285.

Sacks, P. (1997). Standardized testing. Meritocracy's crooked yardstick. Change, 29 (2), 24-31.

Sedlacek,W. E. (2004) Beyond the big test: Noncognitive assessment in higher education. San Francisco, CA: Jossey-Bass.

Shwalb, D. W., \& Sukemune, S. (1998). Help-seeking in the Japanese college classroom: Cultural, developmental, and social-psychological influences. In S. A. Karabenick (Ed.), Strategic help-seeking: Implications for learning and teaching (pp. 141-170). Mahwah, NJ: Lawrence Erlbaum Associates

Shivpuri, S., Schmitt, N., Oswald, F. L., \& Kim, B. H. (2006). Individual Differences in academic growth: Do they exist, and can we predict them? Journal of College Student Development, 47, 69-86.

Slack, W. D., \& Porter, D. (1980). The SAT: A critical appraisal. Harvard Education Review, 50, 154-175.

Stansbury, S. (2001). Accelerated learning groups enhance supplemental instruction for at-risk students. Journal of Developmental Education, 24 (3), 20-40.

Taplin, M., Yum , J. C. K., Jegede, O., Fan, R. Y. K., \& Chan, M. S. (2001). Helpseeking strategies used by high-achieving and low-achieving distance education students. Journal of Distance Education/Revue de l'enseignement à distance, 16(1). Retrieved from http://cade.athabascau.ca/

Tessler, R. C., \& Schwartz, S. H. (1972). Help-seeking, self-esteem, and achievement motivation: An attributional analysis. Journal of Personality and Social Psychology, 21, 318-326.

Thomas, L. L., Kuncel, N. R., \& Credé, M. (2007). Noncognitive variables in college admissions: The case of the noncognitive questionnaire. Educational and Psychological Measurement, 67, 635-657.

Ting, S. M., R. \& Sedlacek, W. E. (2000). Validity of the Noncognitive Questionnaire Revised-2 in predicting the academic success of university freshman. Counseling Center Research Report \#1-00. University of Maryland, College Park. Retrieved from http://williamsedlacek.info/publications/articles/validity100.html

Tracey, T. J., \& Sedlacek, W. E. (1987). Prediction of college graduation using noncognitive variables by race. Measurement and Evaluation in Counseling and Development, 19, 177-184.

Turner, J. C., Midgley, C., Meyer, D. K., Gheen, M., Anderman, E. M., Kang, Y., \& Patrick, H. (2002). The classroom environment and students' reports of avoidance strategies in mathematics: A multimethod study. Journal of Educational Psychology, 94, 88-106.

Urdan, T., \& Schoenfelder, E. (2006). Classroom effects on student motivation: Goal structures, social relationships, and competence beliefs. Journal of School Psychology, 44, 331-349. 
Volet, S., \& Karabenick, S. A. (2006). Help-seeking in cultural context. In S. A. Karabenick \& R. S. Newman (Eds.), Help-seeking in academic settings: Groups, goals, and contexts (pp. 117-150). Mahwah, NJ: Lawrence Erlbaum Associates. Weitzman, R. A. (1982). The prediction of college achievement by the Scholastic Aptitude Test and the high school record. Journal of Educational Measurement, 19, 179-191.

Wood, H. A., \& Wood, D. J. (1999). Help seeking, learning and contingent tutoring. Computers and Education, 33, 153-169.

Zimmerman, B. J. (1998). Academic studying and the development of personal skill: A self-regulatory perspective. Educational Psychologist, 33(2-3), 73- 86.

Zimmerman, B. J. (2001). Theories of self-regulated learning and academic achievement: An overview and analysis. In B. J. Zimmerman \& D.H. Schunk, (Eds.), Self-regulated learning and academic achievement: Theoretical perspectives (pp. 1-37). Mahwah, NJ: Lawrence Erlbaum Associates. 


\section{Help-Seeking Inclination Overall and by Gender}

$\begin{array}{crrr}\begin{array}{c}\text { Help Seeking } \\ \text { Inclination }\end{array} & \text { Women } & \text { Men } & \text { Total } \\ 1 & 14.6 \% & 19.6 \% & 16.7 \% \\ 2 & 9.8 \% & 15.7 \% & 12.3 \% \\ 3 & 15.8 \% & 18.5 \% & 17.0 \% \\ 4 & 15.1 \% & 11.2 \% & 13.5 \% \\ 5 & 17.3 \% & 19.2 \% & 18.1 \% \\ 6 & 9.3 \% & 8.0 \% & 8.8 \% \\ 7 & 8.3 \% & 2.4 \% & 5.8 \% \\ 8 & 5.3 \% & 3.1 \% & 4.4 \% \\ 9 & 1.8 \% & .3 \% & 1.2 \% \\ 10 & 2.8 \% & 1.7 \% & 2.3 \% \\ & 100.0 \% & 100.0 \% & 100.0 \%\end{array}$

TABLE 2

Help-Seeking Inclination as a Function of SAT and Rank

\begin{tabular}{llrrr}
$\begin{array}{l}\text { Median Split } \\
\text { on High School } \\
\text { Percentile Rank }\end{array}$ & $\begin{array}{l}\text { Median Split } \\
\text { on SAT }\end{array}$ & $n$ & $M$ & $S D$ \\
\hline Low & Low & & & \\
& High & 120 & 3.90 & 2.28 \\
& Total & 51 & 2.80 & 2.07 \\
& & 171 & 3.57 & 2.27 \\
High & Low & & & \\
& High & 67 & 4.13 & 1.93 \\
& Total & 117 & 4.06 & 2.14 \\
& Low & 184 & 4.09 & 2.06 \\
Total & High & 187 & 3.98 & 2.16 \\
& Total & 168 & 3.68 & 2.19 \\
& & 355 & 3.84 & 2.18
\end{tabular}


TABIE 3

First-Term GPA as a Function of Help-Seeking Inclination

Self-rated

Help Seeking

$\begin{array}{rrrr}1 & 110 & 2.82 & .72 \\ 2 & 83 & 2.85 & .91 \\ 3 & 114 & 3.04 & .76 \\ 4 & 91 & 3.15 & .64 \\ 5 & 121 & 2.95 & .69 \\ 6 & 58 & 3.03 & .58 \\ 7 & 40 & 3.17 & .55 \\ 8 & 29 & 3.11 & .67 \\ 9 & 8 & 3.14 & 1.02 \\ 10 & 15 & 2.61 & .99 \\ \text { Total } & 669 & 2.98 & .73\end{array}$

$S D$

72

91

.76

.64

69

58

55

67

9

.73 


\section{Profile of Help-Seeking Inclination Levels in Terms of SAT, High School Percentile Rank, First Semester GPA, and Sex (Percent Female)}

\begin{tabular}{|c|c|c|c|c|c|c|c|c|}
\hline \multirow[t]{2}{*}{$\begin{array}{l}\text { Help } \\
\text { Seeking }\end{array}$} & \multirow[b]{2}{*}{$n$} & \multicolumn{2}{|c|}{ SAT } & \multicolumn{2}{|c|}{$\begin{array}{l}\text { High School } \\
\text { Percentile Rank }\end{array}$} & \multicolumn{2}{|c|}{$\begin{array}{c}\text { First-term } \\
\text { GPA }\end{array}$} & \multirow{2}{*}{$\begin{array}{l}\text { Females } \\
\text { Percent }\end{array}$} \\
\hline & & $M$ & $S D$ & $M$ & $S D$ & $M$ & $S D$ & \\
\hline 1 & 59 & 1057.12 & 116.9 & 64.17 & 19.54 & 2.88 & 0.7 & $48.98 \%$ \\
\hline 2 & 49 & 1053.67 & 113.3 & 67.14 & 15.54 & 2.95 & 0.71 & $48.98 \%$ \\
\hline 3 & 61 & 1053.61 & 110.65 & 71.28 & 19.31 & 3.10 & 0.81 & $57.38 \%$ \\
\hline 4 & 46 & 1052.61 & 136.44 & 75.65 & 15.36 & 3.27 & 0.6 & $73.91 \%$ \\
\hline 5 & 62 & 1018.39 & 103.8 & 69.85 & 20.59 & 3.09 & 0.59 & $61.29 \%$ \\
\hline 6 & 33 & 1042.42 & 118.53 & 72.42 & 17.62 & 3.20 & 0.52 & $63.64 \%$ \\
\hline 7 & 17 & 1025.29 & 126.84 & 73.76 & 18.49 & 3.32 & 0.52 & $94.12 \%$ \\
\hline 8 & 9 & 1095.56 & 112.48 & 78.78 & 14.59 & 3.49 & 0.35 & $77.78 \%$ \\
\hline 9 & 4 & 1002.5 & 103.08 & 76 & 18.13 & 3.68 & 0.26 & $100.00 \%$ \\
\hline 10 & 7 & 964.29 & 177.56 & 73.14 & 19.19 & 2.16 & 1.21 & $85.71 \%$ \\
\hline Total & 347 & 1044.03 & 117.95 & 70.33 & 18.48 & 3.08 & 0.7 & $61.67 \%$ \\
\hline
\end{tabular}


TABLE 5

\section{Predicting First-term GPA with Four Models}

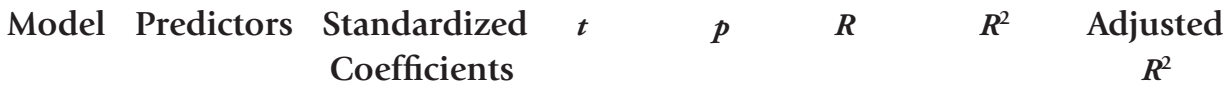

(Beta)

\begin{tabular}{|c|c|c|c|c|c|c|c|}
\hline \multirow[t]{2}{*}{1} & SAT & 0.097 & 1.84 & .067 & \multirow[t]{2}{*}{.416} & \multirow[t]{2}{*}{.173} & \multirow[t]{2}{*}{0.168} \\
\hline & Rank & 0.371 & 7.07 & .000 & & & \\
\hline \multirow[t]{3}{*}{2} & SAT & 0.143 & 2.80 & .005 & \multirow[t]{3}{*}{.493} & \multirow[t]{3}{*}{.243} & \multirow[t]{3}{*}{0.236} \\
\hline & Rank & 0.312 & 6.06 & .000 & & & \\
\hline & Sex & -0.272 & -5.65 & .000 & & & \\
\hline \multirow[t]{4}{*}{3} & SAT & 0.145 & 2.82 & .005 & \multirow[t]{4}{*}{.493} & \multirow[t]{4}{*}{.243} & \multirow[t]{4}{*}{0.234} \\
\hline & Rank & 0.309 & 5.91 & .000 & & & \\
\hline & Sex & -0.269 & -5.50 & .000 & & & \\
\hline & Help & 0.016 & 0.33 & .744 & & & \\
\hline
\end{tabular}

Seeking

4

SAT
Rank
Sex

Help

Seeking

Help

$-0.514$

0.148

\subsection{1}

.004

.515

$5.74 \quad .000$

Sex

0.296

$-5.62$

0.51

3.18

.000

.002

Seeking

Polynomial 
Residuals as a Function of Help-Seeking Level when Predicting First Semester GPA on the Basis of SAT, High School Percentile Rank, and Sex

\begin{tabular}{ccccc}
$\begin{array}{c}\text { Help } \\
\text { Seeking }\end{array}$ & $\begin{array}{c}\text { Actual } \\
\text { GPA }\end{array}$ & $\begin{array}{c}\text { Predicted } \\
\text { GPA }\end{array}$ & \multicolumn{2}{c}{ Residual } \\
\hline & $M$ & $M$ & -0.09 & 0.64 \\
1 & 2.88 & 2.97 & -0.05 & 0.60 \\
2 & 2.95 & 3.00 & 0.02 & 0.68 \\
3 & 3.10 & 3.08 & 0.07 & 0.56 \\
4 & 3.27 & 3.20 & 0.04 & 0.49 \\
5 & 3.09 & 3.05 & 0.09 & 0.49 \\
6 & 3.20 & 3.11 & 0.09 & 0.40 \\
7 & 3.32 & 3.23 & 0.21 & 0.41 \\
8 & 3.49 & 3.29 & 0.42 & 0.07 \\
9 & 3.68 & 3.26 & -0.98 & 1.18 \\
10 & 2.16 & 3.14 & & 0.61 \\
\hline Total & 3.08 & 3.08 & 0.00 & \\
& & & & \\
\hline
\end{tabular}


Help Seeking as a Function of the Interaction of SAT and Percentile Rank

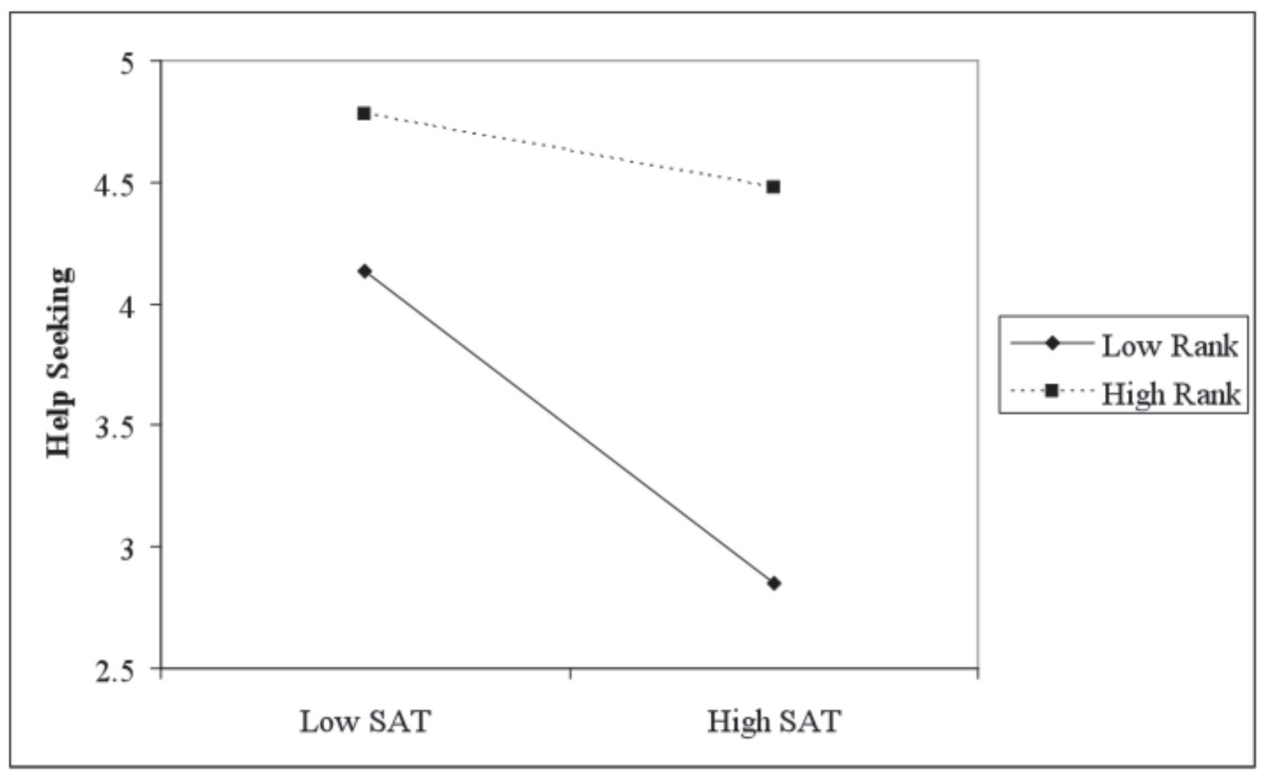

